\title{
ON THE LEGAL MECHANISMS IN CIVIL LAW
}

\author{
Alexey A. Demin \\ Lobachevsky State University of Nizhny Novgorod, Nizhny Novgorod, Russian Federation
}

Introduction: by virtue of Article 8 of the Civil Code of the Russian Federation, civil rights and obligations arise from various grounds. Such grounds are, inter alia, both actions provided for by law, and actions of citizens and legal entities, although not provided for by law, but by virtue of the general principles and the meaning of civil law give rise to civil rights and obligations. At the same time, the legal literature notes that civil rights and obligations have their own legal mechanism of emergence and termination. At the same time, the analysis of the judicial practice shows that in the law enforcement there are difficulties not only with the emergence or implementation of civil rights, but also their termination. In this regard, the author aims to analyze the rules related to the regulation of the termination procedure of civil rights and obligations. Methods: the methodological framework for the research is a set of methods of scientific knowledge, among which the main are the comparative law method, the methods of systematization and analysis. Results: the conclusions made in the research are based on the current civil legislation and existing judicial practice. In addition, the works of the competent scientists on the legal regulation of the emergence and implementation of civil rights and obligations are analyzed. Conclusions: the study concluded that the rules of civil law often do not contain a fixed legal mechanism for the termination of civil rights and obligations. Its absence in the current legislation causes difficulties associated with the achievement of the participants of civil law relations of their goals in the commission of civil actions, as well as difficulties in the law enforcement in resolving civil disputes.

Key words: civil actions, mechanism of legal regulation, legal mechanism, actions of citizens and legal entities, grounds for the emergence of civil rights and obligations.

Citation. Demin A.A. On the Legal Mechanisms in Civil Law. Legal Concept, 2019, vol. 18, no. 1, pp. 112-117. (in Russian). DOI: https://doi.org/10.15688/lc.jvolsu.2019.1.15

\section{О ПРАВОВЫХ МЕХАНИЗМАХ В ГРАЖДАНСКОМ ПРАВЕ}

\author{
Алексей Александрович Демин \\ Нижегородский государственный университет им. Н.И. Лобачевского, \\ г. Нижний Новгород, Российская Федерация
}

Введение: согласно ст. 8 Гражданского кодекса Российской Федерации, гражданские права и обязанности возникают из различных оснований. Такими основаниями являются в том числе как действия, предусмотренные законом, так и действия граждан и юридических лиц, хотя и не предусмотренные законом, но в силу общих начал и смысла гражданского законодательства порождающие гражданские права и обязанности. При этом в юридической литературе отмечается, что гражданские права и обязанности имеют свой со собственный правовой механизм возникновения и прекращения. Вместе с тем анализ судебной практики показывает, что в правоприменении имеются трудности не только с возникновением или осуществлением гражданских прав, но и с их прекращением. В связи с этим автором поставлена цель проанализировать нормы, связанные с регулированием процедуры прекращения гражданских прав и обязанностей. Методы: методологическую основу данного исследования составляет совокупность методов научного познания, среди которых основное место занимают сравнительно-правовой метод, методы системности и анализа. Резуль(?) таты: сделанные в работе выводы основываются на действующем гражданском законодательстве и суще- 
ствующей судебной практике. Кроме того, проанализированы труды компетентных ученых по вопросам правового регулирования возникновения и осуществления гражданских прав и обязанностей. Вывод: в результате исследования сделан вывод о том, что нормы гражданского права зачастую не содержат закрепленного правового механизма прекращения гражданских прав и обязанностей. Его отсутствие в действующем законодательстве вызывает трудности, связанные с достижением участниками гражданских правоотншений своих целей при совершении гражданско-правовых действий, а также затруднение в правоприменении при разрешении гражданско-правовых споров.

Ключевые слова: гражданско-правовые действия, механизм правового регулирования, правовой механизм, действия граждан и юридических лиц, основания возникновения гражданских прав и обязанностей.

Цитирование. Демин А. А. О правовых механизмах в гражданском праве // Legal Concept = Правовая парадигма. - 2019. - Т. 18, № 1. - C. 112-117.-DOI: https://doi.org/10.15688/lc.jvolsu.2019.1.15

\section{Введение}

Действия граждан и юридических лиц в области гражданско-правового регулирования многочисленны и разнообразны. Однако их объединяет то, что они квалифицируются как основания возникновения гражданских прав и обязанностей. Из текста ст. 8 ГК РФ следует, что к правовым основаниям следует относить прямо поименованные в законе действия, которые порождают гражданские права и обязанности, например сделки, а также иные действия граждан и юридических лиц.

Нет сомнений в том, что упорядочение совершаемых лицами действий зависит от их вида и характера. Так, Е.В. Вавилин характеризует особенности правового механизма регулирования действий по осуществлению и защите гражданских прав [3, с. 88-89]. Ю.Н. Андреевым исследуется механизм гражданско-правовой защиты [1, с. 114]. И.А. Еськина в качестве отдельного вида называет действия по приобретению гражданских прав, тем самым выделяя самостоятельную сферу гражданско-правового регулирования [5, с. 166]. При этом даже однопорядковые действия, например совершаемые с целью приобретения гражданских прав, могут порождать различные по своей правовой природе субъективные права и обязанности. Так, действия граждан или юридических лиц могут быть направлены на приобретение вещных либо обязательственных прав [5, с. 166].

Таким образом, нет сомнений в том, что совершаемые гражданами и юридическими лицами действия, будь то это действия по приобретению гражданских прав, действия по их осуществлению или защите, имеют свой механизм правового регулирования.

\section{Виды гражданско-правовых действий и особенности их осуществления}

Е.В. Вавилин обращает внимание на то, что «для функционирования механизма важна четкая согласованность, целесообразность процедур. Известны случаи, когда несогласованность процедурных и основных норм разрушает механизм осуществления прав, ведет к возникновению препятствий на пути осуществления тех или иных прав и обязанностей» [3, с. 88-89].

Самым распространенным видом гражданско-правовых действий, несомненно, выступают сделки, правовым последствием которых чаще всего является установление вещных прав («псевдовещных прав») ${ }^{1}$, а, например, действия по заключению договора, порождающего обязательственные права, сделками не являются и нормами о сделках не регулируются (как можно признать оферту недействительной сделкой и применить к ней последствия недействительности ничтожной или оспоримой сделки?). Вряд ли можно сомневаться и в том, что часть действий гражданско-правовой области однократна, например передача вещи в собственность. Также есть действия, предстающие в виде процесса, например встречное исполнение длящихся обязательств. Сказанное подтверждает существование различий механизмов регулирования действий гражданско-правового характера и обусловливает необходимость их познания.

Вместе с тем в одних случаях правовой механизм законодательно закреплен и понятен, к примеру механизм заключения договора. Так, предписывается совершить действия, связанные с направлением конкретному лицу 
предложения заключить договор (оферта), и действия лица по принятию этого предложения (акцепт). При этом закон определяет содержание оферты, правовые последствия совершения действий по направлению оферты, порядок ее отзыва (ст. 435 ГК РФ), а также порядок совершения действий по принятию предложения о заключении договора, что не вызывает трудностей, связанных с правовой регламентацией действий по его заключению.

В других же случаях такой механизм отсутствует и «превращение» права, закрепленного в общеприменимой норме, в право субъективное становится проблематичным, поскольку действия не получили должной гражданско-правовой регламентации. В качестве примера можно привести положения абз. 2 п. 3 ст. 252 ГК РФ, исходя из которых, собственник не может выделить принадлежащую ему долю в праве общей собственности, а имеет право лишь на денежную компенсацию за свою долю, которая выплачивается другими собственникам. И далее, такая выплата возможна лишь с его согласия (абз. 2 п. 4 ст. 252 ГК РФ). При этом несмотря на то что выражение согласия на получение компенсации за долю вместо ее выдела представляет собой гражданско-правовое действие, влекущее осуществление гражданских прав и обязанностей, в законе отсутствуют нормы, закрепляющие порядок его совершения. Такое положение вещей вызывает трудности в правоприменительной деятельности.

\section{Судебная практика \\ по проблеме правовых механизмов в гражданском праве}

Если обратиться к судебной практике, то обнаружим, что Конституционным Судом Российской Федерации подчеркивается, что в соответствии с абз. 2 п. 4 ст. 252 ГК РФ выплата участнику долевой собственности остальными собственниками денежной компенсации взамен выделяемой доли допускается только при его согласии. И получения согласия не требуется тогда, когда доля собственника незначительная (1), не может быть реально выделена (2) и собственник не имеет в такой доле существенного интереса (3) [6]. При этом Конституционный Суд РФ катего- ричен и указывает, что только наличие всех трех обстоятельств является основанием для игнорирования получения согласия выделяющегося собственника на выплату компенсации. В свою очередь, из разъяснений, содержащихся в п. 36 Постановления Пленума Верховного Суда РФ (далее - Постановление Пленума ВС РФ № 6/8), следует, что суд может признать право на неделимую вещь за одним из участников долевой собственности при условии, что такой собственник имеет существенный интерес в использовании такой вещи, вне зависимости от существующего размера долей иных участников общей собственности с компенсацией стоимости принадлежащей им доли [8]. Таким образом, позиция Верховного Суда РФ отличается от позиции Конституционного Суда РФ и допускает возможность выплаты компенсации без согласия выделяющегося собственника вне зависимости от размера принадлежащей ему доли [6].

О выплате компенсации говорится и в Постановлении Пленума Верховного Суда РФ от 10 июня 1980 г. № 4 [9]. Там указывается, что при невозможности выделяемой доли в праве собственности выплата компенсации определяется соглашением сторон, а в случае недостижения такого соглашения по иску выделяющегося собственника размер компенсации устанавливается судом исходя из действительной ее стоимости. При этом достаточным является согласие выделяющегося собственника на отчуждение доли, даже при наличии спора о размере причитающейся компенсации, что в целом заслуживает поддержки.

Неоднозначная ситуация складывается и с регулированием согласия собственников долевой собственности на выплату компенсации в пользу выделяющегося собственника, выдел доли которого в натуре невозможен. Из все того же п. 36 Постановления Пленума ВС РФ № 6/8 следует, что суд по требованию выделяющегося собственника вправе обязать остальных участников долевой собственности выплатить ему денежную компенсацию, с получением которой сособственник утрачивает право на долю в общем имуществе. При этом ни закон, ни Верховный Суд РФ не разъясняет условия получения согласия участников долевой собственности, на которых возлагается обязанность по выплате компенсации. Это при- 
водит к противоречивым и взаимоисключающим по логике судебным решениям.

Так, по одному делу гражданка Ш. обратилась в суд с требованием о прекращении своего права собственности на принадлежащую ей долю и возложении на остальных участников долевой собственности обязанности по выплате компенсации и приобретении этой доли в свою собственность. Суд первой инстанции заявленные требования удовлетворил. Суд апелляционной инстанции не согласился с выводами суда и указал, что принудительное наделение собственностью не допускается, поэтому требование о принудительной выплате компенсации за принадлежащую долю с переходом на нее прав к остальным участникам долевой собственности не подлежит удовлетворению. При этом ссылаясь на определение Конституционного Суда РФ от 7 февраля 2008 г. [7], закрепляющее общий принцип необходимости достижения соглашения между всеми участниками долевой собственности по условиям раздела общего имущества и его условиях, суд указывает, что недостижение такого согласия не лишает их права на раздел общего имущества или выдел из него доли в натуре. Более того, участник вправе заявить требование о выделе доли из общего имущества. При этом, если выдел невозможен, такой собственник может потребовать выплату ему реальной стоимости его доли другими участниками.

В другом деле аналогичное требование истца суд расценил как неправомерное и не подлежащее удовлетворению, указав при этом, что истец по существу заявил требование о понуждении остальных участников общей собственности к приобретению принадлежащей ему доли в праве общей долевой собственности на жилое помещение. Обязанность по приобретению принадлежащей истцу доли в праве общей долевой собственности на спорное имущество не может быть возложена на ответчиков в отсутствие их согласия. В обоснование принятого решения суд ссылается на п. 1 ст. 9 ГК РФ, в силу которой граждане и юридические лица осуществляют принадлежащие им гражданские права по своему усмотрению, а также ст. 421 ГК РФ, в соответствии с которой граждане и юридические лица свободны в заключении договора и понуждение к заключению договора не допускается.
При этом суд указал, что ссылка на право суда возложить на участников долевой собственности обязанность по выплате компенсации выделяющемуся участнику означает, что сам по себе факт невозможности раздела имущества не может служить основанием для возложения на лицо обязанности приобрести спорную долю помимо его воли [2].

Видно, что проблема закрепления механизма совершения гражданско-правовых действий актуальна не только для приобретения гражданских прав и обязанностей, но и для действий, совершаемых с целью их прекращения. Примером этому может служить и два следующих дела. На рассмотрение Арбитражного суда Нижегородской области поданы два заявления о признании должников несостоятельными (банкротами) с одинаковыми обстоятельствами дела. При рассмотрении дел суд разрешал вопрос о действии выданной единоличным исполнительным органом доверенности лицу, подавшему заявление. Вопрос о действии доверенности возник в связи с требованиями, установленными в ст. 37 Федерального закона от 26 октября 2002 г. № 127-Ф3 «О несостоятельности (банкротстве)» [10], а также требованиями о необходимости проверки полномочий представителя на подачу заявления о признании должника несостоятельным. При этом в одном деле арбитражный суд посчитал доверенность на подачу заявления о банкротстве действующей и, применяя общие положения ГК РФ о полномочиях исполнительного органа юридического лица, рассмотрел заявленные требования ${ }^{2}$. По другому делу суд, применяя положения ГК РФ о прекращении доверенности, принял противоположное решение, оставив заявленные требования без рассмотрения, так как посчитал действие доверенности прекращенным ${ }^{3}$.

В то же время главным является то, что апелляционная инстанция поддержала доводы нижестоящих судов в обоих случаях. Очевидно, что такое положение дел является недопустимым и свидетельствует, что в настоящее время имеются определенные недостатки в использовании гражданско-правовых средств прекращения гражданских прав даже при наличии их регламентации.

Неполнота закрепленного механизма правового регулирования приводит к дестабили- 
зации гражданского оборота тем, что граждане и юридические лица не могут заранее знать о порядке совершения гражданско-правовых действий. Хотя «стабильность гражданского оборота в первую очередь зависит от разработанности правовых средств, обеспечивающих свободное и беспрепятственное осуществление гражданских прав, а также от эффективного механизма установления или приобретения гражданских прав», следует отметить, что «именно направленность на обеспечение поведенческих возможностей правообладателей делает гражданское право надежным инструментом осуществления субъективных прав и средством воплощения в жизнь таких важных принципов, как реальность и гарантированность осуществления гражданских прав» [4, с. 116]. Однако это не всегда учитывается законодателем и приводит к тому, что законодательные конструкции правового механизма суды дополняют толкованием действующих норм права, а в случае невозможности разрешить спор самостоятельно, предлагают обратиться за разрешением к судебным органам.

\section{Выводы}

В заключение стоит отметить, что простое закрепление в ст. 8 ГК РФ перечня гражданскоправовых действий для их надежной регламентации оказывается недостаточным: необходимо еще и детальное правовое регулирование условий и порядка их совершения. Причем в связи с тем, что действия гражданско-правового характера могут совершаться с различными правовыми целями, ощущается потребность оборота в надлежаще действующих механизмах правового регулирования не только действий по приобретению гражданских прав, их осуществлению и защите, а также действий по прекращению гражданских прав и обязанностей. Такие действия должны быть формально упорядочены и понятны всем заинтересованным участникам гражданского оборота. Отсутствие же подобных правовых механизмов влечет невозможность применения базовых норм, устанавливающих субъективные права и обязанности, создает юридическую необеспеченность законных интересов участников оборота, действующих самостоятельно, в случае спора приводит к принятию противоречивых судебных актов.

\section{ПРИМЕЧАНИЯ}

${ }^{1}$ Известно, что существует научная дискуссия о правовой природе залоговых прав и прав аренды. Поскольку автору представляется, что эти права являются правами вещными, но не в том традиционном понимании, как это принято считать, термин «псевдовещные права» является условным и означает особенность вещно-правовой природы данных прав.

2 Определение Арбитражного суда Нижегородской области от 2 апреля 2015 г. по делу № А43-28602/2015.

${ }^{3}$ Определение Арбитражного суда Нижегородской области от 6 марта 2015 г. по делу № A43-28603/2015.

\section{СПИСОК ЛИТЕРАТУРЫ}

1. Андреев, Ю. Н. Механизм гражданско-правовой защиты / Ю. Н. Андреев. - М. : Норма : Инфpa-M, 2010. - 464 c.

2. Апелляционное определение Верховного Суда Республики Татарстан от 23 октября 2017 г. по делу № 33-17092/2017. - Электрон. текстовые дан. - Режим доступа: http://www.consultant.ru/cons/cgi/ online.cgi?req $=$ doc; base $=\mathrm{SOPV} ; \mathrm{n}=347063 \# 073655960$ 63116129 (дата обращения: 13.10.2018). - Загл. с экрана.

3. Вавилин, Е. В. Осуществление и защита гражданских прав / Е. В. Вавилин. - М. : Волтерс Клувер, 2009. - 360 с.

4. Демин, А. А. О соотношении понятий «обеспечение» и «защита» субъективного гражданского права / А.А. Демин // Legal Concept = Правовая парадигма. - 2018. - Т. 17, № 2. - С. 111-118. DOI: https://doi.org/10.15688/lc.jvolsu.2018.2.17.

5. Еськина, И. А. Механизм приобретения гражданских прав : дис. ... канд. юрид. наук / Ирина Александровна Еськина.- М., 2015.-211 с.

6. Определение Конституционного Суда РФ от 7 февраля 2008 г. № 241-О-О. - Электрон. текстовые дан. - Режим доступа: http://www.consultant.ru/cons/ cgi/online. cgi? req $=$ doc $;$ base $=$ ARB002; $=66342 \#$ 035391559717482335 (дата обращения: 13.10.2018). Загл. с экрана.

7. Определение Конституционного Суда РФ от 7 февраля 2008 г. № 242-О-О. - Электрон. текстовые дан. - Режим доступа: http://www.consultant.ru/ document/cons_doc_LAW_49765/ (дата обращения: 13.10.2018). - Загл. с экрана.

8. Постановление Пленума Верховного Суда РФ № 6, Пленума ВАС РФ № 8 от 1 июля 1996 г. «О некоторых вопросах, связанных с применением части первой Гражданского кодекса Российской Федерации». Электрон. текстовые дан. - Режим доступа: http:// 
www.consultant.ru/document/cons_doc_LAW_11279/ (дата обращения: 13.10.2018). - Загл. с экрана.

9. Постановление Пленума Верховного Суда РСФСР от 10 июня 1980 г. № 4 «О некоторых вопросах практики рассмотрения судами споров, возникающих между участниками общей собственности на жилой дом». - Электрон. текстовые дан. - Режим доступа: http://www.consultant.ru/document/cons_doc_LAW_ 6381/ (дата обращения: 10.10.2018). - Загл. с экрана.

10. Федеральный закон от 26 октября 2002 г. № 127-Ф3 «О несостоятельности (банкротстве)» // Российская газета. - 2002. - 2 нояб. (№ 209/210).

\section{REFERENCES}

1. Andreev Yu.N. Mekhanizm grazhdanskopravovoy zashchity [Civil Protection Mechanism]. Moscow, Norma, Infra-M Publ., 2010. 464 p.

2. Apellyatsionnoe opredelenie Verkhovnogo suda Respubliki Tatarstan ot 23 oktyabrya $2017 \mathrm{~g}$. po delu № 33-17092/2017 [Appellate Determination of the Supreme Court of the Republic of Tatarstan Dated October 23, 2017 on Case No. 33-17092 / 2017]. URL: http://www.consultant.ru/cons/cgi/online.cgi?req=doc; base $=$ SOPV;n=347063\#07365596063116129 (accessed 13 October 2018).

3. Vavilin E.V. Osushchestvlenie i zashchita grazhdanskikh prav [Implementation and Protection of Civil Rights]. Moscow, Volters Kluver Publ., 2009. 360 p.

4. Demin A.A. O sootnoshenii ponyatiy «obespechenie» i «zashchita» subektivnogo grazhdanskogo prava [On Relationship between the Concepts of 'Security' and 'Protection' of the Subjective Civil Right ]. Pravovaya paradigma, 2018, vol. 17, no. 2, pp. 111-118. DOI: https://doi.org/ 10.15688/lc.jvolsu.2018.2.17

5. Eskina I.A. Mekhanizm priobreteniya grazhdanskikh prav: dis. ... kand. yurid. nauk [The
Mechanism of Acquisition of Civil Rights. Cand. jurid. sci. diss.]. Moscow, 2015. $211 \mathrm{p}$.

6. Opredelenie Konstitutsionnogo Suda RF ot 07.02.2008 № 241-O-O [Determination of the Constitutional Court of the Russian Federation Dated 07.02.2008 No. 241-O-O]. URL: http://www.consultant.ru / cons/cgi/online.cgi? $\mathrm{req}=\mathrm{doc}$; base $=\mathrm{ARB} 002$; $\mathrm{n}=66342 \# 035391559717482335$ (accessed 13 October 2018).

7. Opredelenie Konstitutsionnogo Suda RF ot 07.02.2008 № 242-O-O [Determination of the Constitutional Court of 07.02.2008 № 242-O-O]. URL: http://www.consultant.ru/document/cons_doc_ LAW_49765/(accessed 13 October 2018).

8. Postanovlenie Plenuma Verkhovnogo Suda RF № 6, Plenuma VAS RF № 8 ot 01.07.1996 "O nekotorykh voprosakh, svyazannykh s primeneniem chasti pervoy Grazhdanskogo kodeksa Rossiyskoy Federatsii» [The Resolution of Plenum of the Supreme Court of the Russian Federation No. 6, the Plenum of the Russian Federation No. 8 Dated 01 July 1996 “On Some Issues Related to the Application of the First Part of the Civil Code of the Russian Federation"]. URL: http:// www.consultant.ru/document/cons_doc_LAW_11279/ (accessed 13 October 2018).

9. Postanovlenie Plenuma Verkhovnogo Suda RF ot 10.06.1980 № 4 «O nekotorykh voprosakh praktiki rassmotreniya sudami sporov, voznikayushchikh mezhdu uchastnikami obshchey sobstvennosti na zhilok dom» [Resolution of the Plenum of the Supreme Court of the Russian Federation Dated 10 June 1980 No. 4 “On Some Issues of Practice of Courts Regarding Disputes Arising between Participants of Common Ownership of a House"]. URL: http://www.consultant.ru/document/ cons_doc_LAW_6381/(accessed 10 October 2018).

10. Federalnyy zakon ot 26 oktyabrya $2002 \mathrm{~g}$. № 127-FZ «O nesostoyatelnosti (bankrotstve)» [Federal Law Dated Oct.26, 2002 No.127-FZ "On Insolvency (Bankruptcy)"]. Rossiyskaya gazeta, 2002, Nov. 2 (No. 209/210).

\section{Information about the Author}

Alexey A. Demin, Candidate of Sciences (Jurisprudence), Associate Professor, Department of Civil Law and Procedure, Lobachevsky State University of Nizhny Novgorod, Prosp. Gagarina, 23, 603950 Nizhny Novgorod, Russian Federation, bullpit@rambler.ru, https:/orcid.org/0000-0003-2450-8776

\section{Информация об авторе}

Алексей Александрович Демин, кандидат юридических наук, доцент кафедры гражданского права и процесса, Нижегородский государственный университет им. Н.И. Лобачевского, просп. Гагарина, 23, 603950 г. Нижний Новгород, Российская Федерация, bullpit@rambler.ru, https://orcid.org/0000-0003-2450-8776 